\title{
Medida e Desmedida: Padronização do Trabalho ou Livre Organização do Trabalho Vivo?
}

\section{Francisco de Paula Antunes Lima}

\author{
Departamento de Engenharia de Produção \\ Universidade Federal de Minas Gerais - Escola de Engenharia \\ R. Espírito Santo, 35, sala 715 - CEP: 30.160-030 - Belo Horizonte - MG
}

Palavras-chave: qualidade total, padronização, ergonomia, trabalho vivo.

\section{RESUMO}

Com a mais nova moda administrativa - a "gerência da qualidade total" (GQT) -, vemos reaparecer velhas técnicas de organização do trabalho e da produção, agora retocadas para servirem a esta ideologia gerencial que se pretende "humanista" e "democrática". Dentre as várias técnicas (algumas delas de comprovada utilidade), até mesmo a "padronização" de inspiração taylorista foi recuperada e "maquiada" para poder se adequar aos nobres princípios da qualidade total; no entanto, sem que se desse muita atenção para a contradição inerente a esta técnica de fundo positivista e reducionista, na medida em que ela procura enquadrar a complexa realidade de uma prática viva em normas ou padrões fixos. Neste artigo discute-se a validade $\mathrm{c}$ a efetividade da padronização do trabalho, nos moldes da GQT, confrontando-a com análises de situações reais. Após esclarecidos seus princípios essenciais e determinada sua filiação taylorista, é mostrado como o trabalho vivo se presta pouco à padronização, isto é, para ser verdadeiramente efetivo e criativo o trabalho deve necessariamente "transgredir" normas e padrões, instituindo sua própria lógica operativa, na medida em que o permite as relações sociais de produção vigentes. Pode-se, então, a partir deste confronto entre os objetivos da padronização e a realidade do trabalho, concluir pela ineficiência das práticas normativas, cujo caráter burocrático e burocratizante decorre do papel limitado que a atividade administrativa, em geral, desempenha no interior da totalidade social e de sua consciência deturpada sobre a natureza da produção e sobre a sua própria natureza. Ao contrário, a justa relação entre "padrão" e "criação" não ć apenas uma questão teórica mas também prática, que só pode ser resolvida no interior da livre organização dos produtores associados, condição indispensável para a auto-regulação da prática coletiva pelos próprios indivíduos que trabalham. 


\section{Introdução}

As recentes mutações da produção e do mercado mundial têm exigido a reorganização de empresas e de setores produtivos inteiros. Novas formas de organização do trabalho e da produção, assim como as teorias e os conceitos correspondentes, são sugeridas para atender as necessidades das empresas em busca de competitividade. Dentre as propostas existentes, a "Gerência da Qualidade Total" (GQT ou simplesmente QT - "Qualidade Total") é sem dúvida a que ganhou maior divulgação no Brasil e em vários outros países, impulsionada pela emergência do Japão como força econômica. É natural que as "novas" teorias administrativas, para atender as demandas concretas, se sirvam de princípios, técnicas e métodos desenvolvidos e validados por práticas anteriores. Neste sentido a QT é de uma modéstia sem par, afirmando freqüentemente que se limita a utilizar o existente, pouco tendo de propriamente inovador. Assim, podemos presenciar a revalorização de técnicas estatísticas no controle da qualidade, a volta da análise de valor na concepção de produtos, a recuperação das concepções humanistas da Escola de Relações Humanas, a adoção de princípios e técnicas de organização inspirados pelo taylorismo; etc. $\mathrm{O}$ "novo" seria, então, a reorganização desses antigos princípios e técnicas sob o valor máximo da "qualidade", que hoje (sobretudo após o suposto fím da produção de massa) tenderia a se impor como princípio norteador da produção. Esta incorporação se faz, no mais das vezes, sem nenhum distanciamento, sem se atentar para a pertinência e real efetividade do que foi resgatado e desconsiderando todas as críticas já feitas. Todavia, por mais desavisados que sejam os divulgadores da QT (comumemente engenheiros sem formação em ciências sociais), eles sabem (ou ouviram falar) das críticas que pesam sobre Taylor e sua famosa "Orgarização Científica do Trabalho" (OCT), devendo, portanto, tomar alguma distância desse autor, ao se servirem de seu legado. Mesmo assim, veremos que a identidade entre OCT e GQT é significativa, apesar dos votos em contrário dos ideólogos da QT, em vários aspectos essenciais, particularmente no que diz respeito à padronização do trabalho, objeto deste artigo.

A padronização é incorporada à GQT como uma contribuição dos modelos japoneses, essencial para a implementação de programas de QT, nem sempre, contudo, sendo explicitada a paternidade taylorista. Uma vez reconhecida sua filiação, procuraremos avaliar sua eficiência prática e a eventual contraditoriedade com outros princípios da QT, em especial, a "participação", a "iniciativa" e o "desenvolvimento pessoal" dos trabalhadores. Não se trata aqui de discutir todos os aspectos relacionados à padronização, mas tão somente a padronização das atividades dos trabalhadores. O essencial de nossa crítica (que será sustentada por análises de situações reais) é que a "padronizacão do trabalho" constitui uma contradicão nos termos. Otrabalho (como qualquer outra atividade humana) não se presta, por sua natureza, à padronização. $O$ que pode ser útil e altamente positivo no caso da especificação de produtos, materiais e equipamentos, contribuindo para a qualidade da produção (basta lembrar as vantagens da intercambialidade) representa, no caso do trabalho vivo, a negação de suas melhores qualidades. 


\section{"Padronização Participativa" ou "Padronização Taylorista"?}

A GQT pretende ser superior à OCT de Taylor, se autoqualificando de "humanista", "democrática", "participativa" na medida em que possibilitaria o desenvolvimento pessoal dos trabalhadores, propiciando-lhes um trabalho "criativo". Mesmo herdando várias idéias do taylorismo, a adoção da concepção de homem fornecida pela Escola de Relações Humanas (ERH) seria suficiente para depurálas de seu caráter autoritário. Vale a pena, então, antes de tratarmos diretamente da padronização, esclarecer as relações entre essas teorias administrativas. Quando se compara com a devida atenção (para além das declarações de boa-fé) os princípios essenciais do taylorismo e aqueles professados pela GQT, ver-se-á que é impossível não se concluir pela identidade fundamental entre as duas teorias. Neste curto espaço só podemos mencionar algumas caracteristicas gemelares fundamentais, deixando a discussão em detalhe para a questão da padronização. Para tanto, confrontaremos a descrição da GQT feita por Campos (1992a, 1992b) e a exposição que o próprio Taylor faz de seu sistema no clássico Principios de Administrą̧ão Cientifica.

É sabido que o taylorismo se caracteriza por uma ideologia hierarquizante da gestão, separando organizadores e executantes. Esta divisão social do trabalho é reafirmada pela
GQT, onde a "participação" se resume em transformar o trabalhador "no gerente de sua própria máquina". Ambas as teorias hierarquizam a sociedade, negligenciando as contradições sociais e naturalizando as classes e grupos em conflito, na mesma medida em que os transformam em membros de um só organismo, repetindo a fábula de Menênio Agripa, que dizia ser impossivel que os escravos se rebelassem contra os seus senhores, tanto quanto o estômago contra o cerébro. Com tal concepção orgânico-funcionalista do ser social, conflitos de interesses aparecem como absurdos e fica fácil sustentar a harmonia necessária entre os diferentes agentes envolvidos na produção. Igualmente interessante é a solução encontrada para amalgamar esta mal costurada estratificação social. Em ambos os casos, o "consumidor" é eleito como valor máximo e principio regulador da prática produtiva, entidade abstrata que confratemiza gregos e troianos ${ }^{2}$. Decorre dai o cientificismo de ambas as teorias.

Taylor considerava como essência do seu método a determinação "científica" de um salário justo e de uma jornada normal de trabalho que resolvesse as eternas querelas entre patrões e trabalhadores, eliminando a oposição destes ao aumento da produção (de fato, à intensificação do trabalho). As divergências só permaneciam porque uns e outros não estavam ainda cientes dos métodos científicos de administração. Essa visão positivista e estreitamente cientificista é também a marca registrada da GQT, segundo a qual qualquer problema pode ser resolvido pelo "método cartesiano", baseado em "fatos e

\footnotetext{
'- Nun artigo anterior (LIMA, 1993) jà mostramos porque essa participação é necessariarnente limitada.

2- Taylor defendia suposios "direitos do povo (...) superiores aos interesses dos empregados e dos empregadores", afirmando que a racionalização da produção redundava em beneficios para o "público enn geral" (p 123). Como é notório a QT elege o "cliente" como "rei". Enbora a categona de "cliente" se aplique, tanto aos utilizadores intemos (trabalhadores, seções, postos de trabalho) quanto aos externos, de fato é a "soberania do consumidor" que prevalece. Vemos que nem neste aspecto a QT soube inovar. Para uma critica da "soberauia do consumidor" ver LIMA (1993) e MANDEL (1991)
} 
dados" (CAMPOS,1992b). Ambos enfatizam a "educação" e vêem a conscientização como panacéia dos conflitos do mundo do trabalho.

Vale lembrar, também, que Taylor, em decorrência de sua concepção positivista de ciência, procurava mostrar "que os princípios fundamentais da administração científica são aplicáveis a todas as espécies de atividades humanas", em "qualquer atividade social", dos lares às igrejas (p. 28). Do mesmo modo, uma das pretensões mais criticáveis da GQT é a sua suposta "universalidade", cujos principios e técnicas se aplicariam tão bem em indústrias como em escolas e hospitais (desconheço se já tentaram aplicá-los às igrejas...). Ambas se fundam, portanto, numa universalidade demasiadamente abstrata, que termina por desconhecer as especificidades dos diferentes objetos.

Mas o que dizer da exaltação do ser humano pela GQT? Essa seria, em princípio, a marca distintiva em relação ao taylorismo, facultada pela concepção humanista da ERH. Para avaliar a correção dessa afirmação, é preciso antes confrontar a OCT com a ERH. Tradicionalmente, se considera as pesquisas de E. Mayo como o ponto de ruptura com o taylorismo e sua concepção do homo economicus, suplantado por uma visão mais globalizante do "fator humano", um ser também carente de afeto, desejoso de realização pessoal, responsável e capaz de iniciativa. Mas é verdade que esta nova concepção cafacterizaria uma ruptura radical com os princípios da OCT? Para estabelecer tal diferença, foi antes preciso caricaturar de tal maneira o taylorismo, que a pieguice do discurso da ERH apa- recia como a própria redenção do trabalho. Todavia, hoje sabemos que esse discurso humanizante esconde formas de manipulação bem mais refinadas, obtendo a adesão dos trabalhadores através de relações afetivas com o trabalho, os colegas e a empresa. Tal como no caso de Taylor, procurava-se intensificar o trabalho através do mascaramento dos conflitos de classe e do retoque artificial de um trabalho que continuava sem sentido e conteúdo. No entanto, é possivel mostrar, para além dessa critica já bem conhecida, outras identidades entre as duas escolas gerenciais. Ressaltaremos, apenas, que ambas se apoiam sobre uma concepção naturalista do homem, mudando somente as dimensões enfatizadas. (para se convencer disso é suficiente lembrar a conhecida hierarquia de necessidades de Maslow, também acriticamente retomada pela QT). A diferença, portanto, é apenas de grau, razão pela qual a GQT consegue acomodar tanto os princípios da OCT quanto aqueles da $E H^{3}$. A incorporação do discurso pseudohumanista se adapta bem à visão mecanicista do taylorismo, na medida em que propicia o contraponto necessário ao trabalho desumanizado. A concepção de homem da ERH, portanto, não exime a GQT de sua filiação taylorista e nos solicita a identificar seus fundamentos comuns.

Os princípios mais gerais da OCT e da GQT - o cientificismo, a harmonia social, a hierarquia, a ênfase na educação e na conscientização, o universalismo abstrato, o humanismo naturalista - refletem uma natureza comum, de teor ultra-racionalista e idealista, cuja contrapartida necessária é a acomodação da complexa realidade da produção no leito

\footnotetext{
1. Poderiarnos ir mais longe e afimmar que essa diferença é bem menor do que se imagina. Apoiado numa análise de documentos originais da Taylor Sociely, Doray (1981:96) pode mostrar que, "contrarianente a uma idèia bastante difundida, os fundadores da <<gerência cientifica > estavam longe de negligenciar a importância do <<fator humano >. Numerosas publicações testemunham seus esforços para apreender, numa perspectiva adaptativa, as atitudes, os sentimentos e os comportamentos." Esta tentativa de adaptação do trabalho à lógica abstrata do capital é, portanto, o qute mais profundamente identifica a OCT à ERH.
} 
de Procusto de alguns poucos princípios formais ${ }^{4}$. Esse reducionismo da teoria se manifesta, igualmente, nas técnicas, metodologias e ferramentas desenvolvidas para implementá-la. Não é à toa, por exemplo, que objetos de naturezas tão distintas como o trabalho humano e o funcionamento de máquinas e matérias-primas sejam arrolados sob os mesmos princípios e conceitos. Vejamos como isso se passa no caso da padronização.

\section{A Padronização segundo a Qualidade Total}

Na GQT a padronização é tida como a "mais fundamental das ferramentas gerenciais" e a base para "o gerenciamento da rotina do trabalho diário" (CAMPOS, 1992a:1). Mas como se define a padronização no âmbito da GQT? Segundo este mesmo autor "padronizar é reunir as pessoas e discutir o procedimento até encontrar aquele que for melhor, treinar as pessoas e assegurar-se de que a execução está de acordo com o que foi consensado (sic)" (Ibid, p. 3). A crer nos seus prosélitos, estariamos aqui diante de uma prática realmente democrática e participativa, em tudo distinta da padronização taylorista, que seria "em sua grande parte voluntária, ou seja, as pessoas discutem aquilo que será padronizado, estabelecem o procedimento padrão e o cumprem". Além disso, "sua alteração é possível e até incentivada como forma de se melhorar os processos" (Ibid. p.3). Esta primeira impressão é reforçada pelo cuidado que o autor demonstra ao definir "padrão", diferenciando-o de "norma". Aprendemos que o primeiro termo é o "que melhor define a padronização como um movimento democrático e natural", pois "norma" teria a cono- tação de obrigatoriedade. Ao contrário, o "termo padrão (...) refere-se a tudo que severifica e simplifica para o benefício das pessoas. (...) O padrão é consensado e pode ser alterado". (Ibid, p.121, grifos no original). Em suma, o ponto central é a definição consensual de um procedimento padrão, que pressupõe a participação voluntária das pessoas envolvidas. Este processo, no entanto, não é tão natural quanto parece. Dois tipos de objeção podem ser formuladas a este propósito: uma, mais genérica, referindo-se à possibilidade mesma de obtenção do consenso, outra sobre a suposta eficiência do padrão (supondo possível o consenso).

O consenso é objeto de debates intensos em várias áreas das ciências sociais, e ainda não se obteve consenso sobre a forma de obtêlo, e mesmo se isso é jamais possível. A discussão em torno de uma racionalidade da ação comunicativa (Habermas) é bastante ilustrativa sobre as dificuldades de se fundamentar universalmente e formalmente a solução de problemas práticos através do consenso (ver, por exemplo, THOMPSON \& HELD, 1982). Finalmente, e isso nos concerne mais de perto, é questionável a eficiência real dos padrões para regular, tanto as ações sociais, quanto a atividade de trabalho. Nosso autor, coerente com sua fé racionalista, crê que o consenso firmado em teoria possa realmente traduzir-se em práticas uniformes e eficientes. Por isso, “a padronização só termina quando a execução do trabalho, conforme o padrão, estiver assegurado". (CAMPOS, 1992a, p. 3).

Aqui, a proximidade com Taylor e o seu famoso princípio do "the one best way" torna-

4- Nada mais revelador, neste contexto, que a "administração" seja considerada como a causa e a cura dos males suciais. Marx já criticara a insuficiência da prática adıninistrativa para resolver problemas sociais. Contra A. Ruge afinnava que a "imposência" é a "lèalural da admninistração". A crenç̧a na administraçâo apenas reitera um circulo vicioso: "se os problemas são diagnosticados como sendo provocados por 《defeitos de adıninistração $>$, nada mais natural que propor medidas de administração". (MARXGlosas marginais criticas ao artigo "O Rei da Príssia e a Refonna Social". Grifos no original). 
se demasiadamente perigosa, exigindo uma demarçação mais explicita por parte da GQT. Acreditam seus defensores que "os japoneses, ao iniciarem seu trabalho de desenvolvimento de um modelo próprio de Gestão da Qualidade, mantiveram o mesmo principio taylorista para a padronização, ou seja, a padronização deveria ser a busca e a adoção sistemática de melhores métodos, visando obter melhores resultados. Porém, a forma de estabelecer padrões deveria ser diferente da prática taylorista. A padronização não deveria ser responsabilidade única de um corpo técnico especializado, mas responsabilidade coletiva de cada uma das pessoas de uma organização nos seus diferentes niveis de atuação". (COELHO \& XAVIER, 1993: 5; grifos no original). Ou seja, o erro de Taylor não estaria em seus princípios teóricos, mas em sua "prática", mais precisamente em estabelecer um "corpo técnico especializado" como único responsável pelo estabelecimento de padrões. Aprendemos, assim, que toda a crítica contemporânea ao taylorismo tem errado de alvo ao ver o defeito em seus princípos teóricos, tidos como "positivistas", "reducionistas", "não sistêmicos", "inadequados para a compreensão do trabalho humano", etc. O problema residiria exclusivamente na "forma" em que eles foram aplicados. Aliás, é bem típico de Taylor (como também dos defensores do GQT) separar os "princípios" de sua forma de aplicação. Já no seu tempo, quando a OCT encontrava resistências, Taylor alertava repetidamente para as incompreensões relativas à "essência" de sua administração científica. Desse modo, as resistências seriam ocasionadas pelas "aplicações ou compreensôes errôneas", os princípios permanecendo intactos. Vejamos, então, a solidez dos mesmos princípios.

O essencial da padronização é, pois, "a procura (consensual) das melhores maneiras de trabalhar". Em principio, isso nada tem de errado. Como alguns autores têm mostrado, isso nada mais é que defender o uso da ciência em benefício de uma organização mais racional do trabalho, e seria, portanto, necessariamente irracional se posicionar contra tais intenções. (para a defesa do taylorismo nesses termos ver sobretudo MONTMOLLIN, 1981)). No entanto, não colocamos em questão o objetivo de procurar as melhores maneiras de trabalhar mas, se existe, como prêtendia Taylor, "a melhor maneira de se realizar uma tarefa é que esta melhor maneira levaria a um melhor resultado". (COELHO \& XAVI$\mathrm{ER}, 1993: 5)$. A dúvida incide precisamente sobre o número, mas a diferença é de peso, implicando concepções opostas sobre a realidade da produção, do trabalho, de organização e finalmente da própria ciência do trabalho. É toda a distância que separa o abstrato princípio taylorista do "the one best way" da diversidade das situações de trabalho e dos homens reais, que, ao contrário, exige a pluralidade das formas de trabalhar. Quando se adota esta última perspectiva, ver-se-á que "padrão" e "participação" são auto-excludentes, isto é, uma "padronização participativa" ou "voluntária" é, no melhor dos casos, uma contradição que não pode se realizar na prática ou, quando se efetiva, aparece como um pesadelo onde o morto domina o vivo. É questionável, portanto, se a simples participação significa uma mudança de fundo dos princípios da padronização à la Taylor.

\section{A Padronização segundo Taylor}

Com efeito, o que está explicitamente dito e implicito na idéia de padronização em Taylor? Em Principios de Administração Cientifica podemos ler sobre a padronização: "A inteligência de cada geração [de trabalhadores] tem desenvolvido métodos mais rápidos e melhores para fazer as operações nos 
diferentes trabalhos. (...). Entretanto, (...) dificilmente é encontrada uniformidade na execução "E exemplifica: "Em lugar dum processo que é adotado como padrão, há usualmente, digamos 50 a 100 processos diferentes de fazer cada tarefa". (p.46). É esta situaçâo intoleravelmente "anárquica", que motiva inicialmente Taylor a elaborar uma ciência do trabalho capaz de definira "melhor maneira de trabalhar", portanto capaz de evitar os desperdícios oriundos da "má administração". O defeito da administração tradicional estava em deixar inteiramente aos trabalhadores a iniciativa de criar e adotar novos métodos, de forma simplesmente empírica, não científica.

Já se comentou suficientemente sobre a transferência do saber operário para a gerência, um dos princípios e efeito principal do taylorismo. Porém, o essencial aqui não é tanto a apropriação de um saber já existente, quanto o controle do processo de geração, aperfeiçoamento e transmissão do conhecimento. Ao contrário do que se alardeia, Taylor não menosprezava a inteligência e a iniciativa dos trabalhadores; as reconhecia desde que se manifestassem no interior de seu sistema, o único capaz, aos olhos de seu criador, de desenvolver sem entraves a ciência do trabatho. A divisão entre concepção e execução obedecia mais a questões circunstanciais, do que a um princípio teórico ou à intenção de controle. Pragmaticamente,Taylor reconhecia um estado de coisas existente (a divisão social do trabalho) e a oficializava, atribuindo aos gerentes e a seu staff a responsabilidade de elaborar a ciência do trabalho, selecionar e treinar os trabalhadores'. O seu erro maior está na própria concepção de cientificidade e da natureza do trabalho, erro que é reiterado pelo principio da padronização, mesmo quando se lhe acrescenta o epíteto "participativa". Assim, não há diferença fundamental entre o princípio taylorista de separação entre concepção/execução do trabalho e a recomendação da QT de que os gerentes mantenham o "domínio tecnológico" emseus setores (CAMPOS, 1992a:8-9). O que ambos visam é transferir o controle do processo de geração de conhecimentos para as mãos da gerência, a hierarquia, apesar da participação, permanecendo intacta. Esta é, todavia, veremos mais tarde, uma vitória de Pirro. Na medida em que a ciência positivista deve lidar somente com leis gerais, escapa-lhe forçosamente as determinações particulares e singulares das situações concretas. Mais ainda, porque um dos fundamentos da produção ainda é o homem (o trabalho vivo) dotado de vontade e de interesses próprios, é preciso recuperar concretamente e em permanência o controle e "dominio" mantidos apenas abstrata e formalmente. Dilema que se repõe em cada ato de trabalho.

\footnotetext{
s- A atribuição da OCT à gerência é justificada pela "falta de tempo e de oportunidade" para que os próprios trabalhadores possaun desenvolver as complexas leis da "ciência do trabalho" (TAYLOR, 1970:97). Mesino dispondo de capacidade intelectual suficiente, os trabalhadores estarian "materialmente impossibilitados de trabalhar, ao mesino tempo, na maquina e na mesa de planejanento." (p. 50). Tendo unta concepção naturalista das aptidões humanas, Taylor não nega que alguns trabalhadores possann ser dotados de inteligência. (e que possan contribuir à elaboração da ciência do trabalho, se desenvolver e realizar trabalhos nais elevados e condizentes com suas capacidades comprovadas). Esse lado de seu pensamento é completamente obscurecido pela indigração que provoca o famoso exemplo do operário do "tipo bovino". A opção pela Inanutenção da divisão social do trabalho é ıneramente pragmática, senıđo reforçada pela lecessidade de vencer as resistências imediatas e impor os novos princípios. Comprova-o o fato de que, mesıno pregando a identidade de interesses, Taylor ainda guardava uma profunda desconfiança dos trabalhadores (pp 88, 97), incapazes, tanto quando os adininistradores, de percubereın de imediato as vantagens de seu sistema. É fäcil ver que tal situação perduraria, na visão de Taylor, enquanto todos ıão estivessem plenamente conscientizados da comunidade de interesses, das vantagens a da necessidade da cooperação. É igualınente significativo que Taylor e a QT recorram à relação professor-aluno, estendendo-a as relações sociais: dizia o prineiro que "todos nós soinos crianças grandes"(p 115), enquarto o segundo afirna que a "adininistração é o professor e o executor da tarefa, o aluno". (CAMPOS, 1992a:73)
} 


\section{A filosofia geral da padronização}

O que está subentendido nas duas concepções gerenciais pode ser resumido em alguns princípios gerais, típicos de uma visão determinista e mecanicista do mundo, inconciliável com a liberdade humana. Os gerentes japoneses reconhecem que "quem executa uma função sabe mais dela que qualquer outra pessoa" (Sochiro Honda, citado naFolha de São Paulo, 13.2.94,p 7.1); o que soa como um reconhecimento inconteste da autonomia dos trabalhadores. Isso, porém, não significa que se reconheça a verdadeira natureza do trabalho, que, para se efetivar, requer, não somente conhecimento geral, mas também (e sobretudo) saber prático, impossivel de ser resumido em algumas poucas fórmulas abstratas. $\mathrm{Na}$ QT, o trabalhador, mesmo sendo o que melhor sabe de sua tarefa, ainda é considerado como "executante" de um plano previamente traçado.

Esse princípio essencial da padronização é compartilhado por visões de mundo e práticas mais amplas, todas se caracterizando pelo que Lukács (1989:58) denominou, se referindo à planificação da economia por um organismo central e burocrático, de "apoditicidade abstrata", com o agravante de que "freqüentemente elas se apoiam em extrapolações infundadas". As suas características mais essenciais são a abstratividade e a normatividade que pressupõem uma forma estreita de racionalidade. "A racionalização é limitada a um tipo de racionalização que funciona como um modelo normativo, considerado como o único permitindo a obtenção da eficiência, e aplicável a todas as classes de situação. Tratase, evidentemente, do modelo determinista de organização que repousa sobre três princípios: 1) uma teoria do comando, segundo a qual pode-se definir do exterior o comportamento do sistema comandado; 2) a previsibilidade $\mathrm{e}$ a estabilidade do ambiente supostamente conhecido e perfeitamente modelizável; 3) a padronização dos procedimentos e a normalização do trabalho e de sua organização" (TERSSAC \& DUBOIS, 1992). Esse tipo de teoria organizacional tem sido objeto de críticas recentes, precisamente por não atender às necessidades de reorganização da produção. Em resposta à ineficiência desta racionalização estreita, têm surgido novas formas de organização e teorias mais congruentes com a variabilidade e complexidade dos sistemas reais.

\section{Padronização do Trabalho ou Auto- Organização dos Trabalhadores?}

Um dos fatos mais perturbadores para a ideologia da padronização nos é revelado pelo paradoxo da "greve do zelo" ou "operação-padrão". Se a padronização fosse onec plus ultra da garantia da qualidade e do bom funcionamento de um sistema de produção, por que seguir à risca os padrões acaba por inviabilizar ou reduzir drasticamente a produção? Com efeito, o que nos ensina a greve do zelo? Se o cumprimento estrito dos padrões é prejudicial à produção, não seria porque aí se revela uma contradição, isto é, porque o trabalho não é (e não pode ser) padronizável? Duas respostas seriam possíveis para salvar o princípio: atribuir tais fatos à inadequação dos padrões ou por estes serem inacabados. Em ambos os casos, a solução seria o aperfeiçoamento dos procedimentos, qualquer divergência sendo caracterizada como "anomalia". As falhas dos padrões se corrigiriam com... mais padronização, sem que o princí- 
pio mesmo seja contestado. Tudo se passa como se o mundo fosse um mecanismo laplaciano, completamente previsivel e formalizável através de padrões e de procedimentos. $O$ idealismo é visivel: não se trata de (re)conhecer a variabilidade e relativa indeterminação do real (do qual também faz parte o acaso), conceber formas de organização e agir em consequência, mas de conformar a realidade complexa a alguns princípios e regras estabelecidas à priori (é significativo que os livros de CAMPOS 1992a 1992b sejam quase inteiramente escritos no imperativo!). Daí a supervalorização da conformidade, da educação e do treinamento, da repetibilidade, da rotina, do consenso, da simplificação como princípios e objetivos essenciais de organização. Em verdade, não é a eventual imperfeição dos padrões que dificulta seu cumprimento, mas a inadequação intrinseca do próprio princípio de padronização - a uniformidade - para dar conta da variabilidade imanente às coisas.

Também não explica o paradoxo da greve do zelo a circunstância dos padrões estarem ainda inconclusos. Por que ainda não se conhece o trabalho em todos os seus detalhes, não se pode estabelecer padrões que lhe correspondam em toda sua extensão. Temos aqui apenas a outra face da visão mecanicista do mundo; se este consiste num mecanismo de relógio, bastaria então a ominisciência do relojoeiro para controlá-lo (papel que evidentemente cabe à gerência). Assim, é simples questão de tempo (eis porque a qualidade e a padronização se fazem passo a passo) até que todo o mecanismo da produção e do trabalho seja conhecido e planejado. Ora, o fato é que esta ominisciência não é jamais alcançada. (e é sensato duvidar que ela seja ao menos possível, dada a complexidade intensiva e exten- siva da natureza). Além disso, malgrado o que afirma seus divulgadores, é bem pouco crivel que a padronização seja realmente o cerne do progresso, ou seja, se o controle e a melhoria da produção é conseguida graças e, principalmente, à maior formalização dos procedimentos, e pela obediência estrita aos padrões. Nossa critica não consiste em negar as virtudes de todo e qualquer conhecimento já formalizado (seria cair no irracionalismo), mas atinge a concepção positivista da ciência que subtende os princípios da OCT e da QT, que antes de serem objetivos (como deve ser toda ciência) sãoobjetivistas . (sobre o processo de coisificação da atividade de trabalho subentendido no taylorismo e na QT, ver LIMA, 1993).

Pena (ou felizmente) que a realidade não se submeta tão facilmente quanto as palavras à vontade dos engenheiros. Um mundo assim tão comedido seria não somente monótono, mas representaria o fim mesmo de qualquer evolução, mais próximo das anti-utopias que da tão sonhada harmonia. Com efeito, somente o surgimento de problemas (e não de simples "anomalias") inesperados e indefinidos, motiva a criatividade e a engenhosidade humanas; por isso a história existe e nos reserva sempre surpresas. Uma outra concepção de ciência e da própria realidade do trabalho e da produção faz-se necessária para melhor entender esse paradoxo. De certa forma algo já ficou subtendido nas críticas anteriores. A tese que sustentamos é que a melhoria da produção não se funda na "obediência aos padrões", mas, sobretudo, na desobediência, como mostrado pelos estudos de situações reais de trabalho, realizados pela sociologia do trabalho e pela ergonomia ${ }^{6}$.

6. Unn exemplo mais prosaico pode nos ajudar a melhor perceber o problema. Quem já colocon a mão na massa sabe muito bem que uma receita de cozinha é sempre ıum bơn começo para preparar un prato, mas nunca suficiente. Por outro lado, tentar extrair e formalizar o saber de un bom cozinheiro é tão dificil quanto querer reproduzir "aquele prato que a manãe fazia". Finalmente, não há dois cozinheiros que concordem sobre a "Inelhor maneira" de se fazer un prato. Poder-se-ia atribuir tais fatos ao estado "pré-cientifico" da culinária; a verdade, porém, é que nenhum processo industrial consegue obter aqualidade da cozinha caseira... 


\section{A Natureza Anti- Padrão do Trabalho}

Ao contrário do que afirmam a OCT e a GQT, não é a uniformidade que garante resultados ou permite melhorar a produção. Para que isso aconteça é preciso sempre que os trabalhadores desobedeçam, recriem e criem em permanência suas próprias regras e "padrões". Nesse sentido (se ainda podemos falar em "padrões"), a racionalidade própria ao trabalho vivo é contraditória com o formalismo clarividente e reducionista da padronização. A lógica do trabalho é, sobretudo, uma "lógica prática", contextualizada, sempre mais complexa (e rica) do que os simplismos das regras e padrões deixam entrever. Para compreender isso é preciso adotar uma posição mais respeitosa da realidade própria das coisas, tanto do trabalho, (comportamento humano) quanto da própria produção com todos os seus componentes. Somente então podemos entender como se relacionam em toda a sua complexidade a teoria e a prática, o mesmo (universal) e o diverso (as singularidades), o formal $\mathrm{e} o$ informal, a causalidade e casua- lidade, sem cairmos no pragmatismo cego ou na clarividência inerte. A "racionalidade prática" do trabalho é precisamente a união complexa dessas categorias que o taylorismo e a GQT tendem a isolar, hipostasiando as dimensões do formal e do mesmo. Vejamos alguns exemplos concretos.

A ergonomia de língua francesa tem mostrado que a variabilidade é característica ineliminável do trabalho, mesmo aqueles tidos como "rotineiros" e "repetitivos". Nossas próprias observações de campo permitiram mostrar que atividades realizadas em ciclos na escala do segundo, apresentam grande diversidade, não somente quantitativa, mas qualitativa; pequenos gestos são acrescentados, por iniciativa dos próprios operadores, aos modos operatórios prescritos, a fim de que eles possam realizar o trabalho na quantidade e na qualidade desejadas. Em qualquer caso, verifica-se a regra geral de distinção entre "trabalho prescrito" e "trabalho real", tradicionalmente revelados pelas análises ergonômicas do trabalho. A natureza dessa diferença ineliminável pode ser melhor entendida através da análise de uma situação mais comple$\mathrm{xa}$, resumida no quadro abaixo.
Numa fábricade produtos eletrônicos, toda a produção é rigorosamente controlada em função dos requisitos de garantia da qualidade (especificações, controle, rastreabilidade, etc). Uma análise detalhada foi realizada num setor de produção, envolvendo as atividades de mecânicos, (controle do processo), operadoras (alimentação e inspeção) e controladoras de qualidade. (reinspeção e liberação). Como de costume, em estudos ergonômicos, pudemos verificar que, apesar das instruções e procedimentos ricamente detalhados, os padrões estabelecidos eram insuficientes para explicaros resultados em termos de produção e de qualidade. As metas eram obtidas graças ao recurso a procedimentos informais, às vezes contrariando as normas escritas. Estas atitudes só são compreensiveis se se consideram os trabalhadores capazes de iniciativa (tal como no caso revelado pela operação-padrão), e, neste caso, sem que se precisasse dos estimulos dos programas de QT. (A empresa obviamente desenvolvia programas voltados para a qualidade, mas apenas convencionais, sem nenhuma ideologia explicita). Esta implicação "espontânea" corresponde melhor à natureza do trabalho humano que, longe de ser uma mera atividade técnica, apresenta dimensões sociais, dentre as quais aquelas de na- 
tureza ética. O envolvimento dos trabalhadores é, portanto, guiado por interesses morais onde se entrelaçam, de maneira complexa,o respeito pela qualidade do produto, a economia de materiais, a cooperação com os colegas, tudo isso entremeado pela coerção da chefia, pela recriminação pública dos erros, etc. O que aparece dessas observações é que a racionalidade do trabalho dificilmente pode ser apreendida somente em termos de racionalidade instrumental, caso em que os padrões se aplicariam com mais facilidade. Un inico exemplo poderá deixar mais claroa que tipo de racionalidade nos referimos. No setor en questão, prevê-se (em função da garantia da qualidade) que todo o lote correspondente a uma hora de produção seja rejeitado quando o controle de qualidade encontra, na inspeção poramostragem, alguma peça defeituosa. Os critérios de decisão são bem precisos e estatisticamente definidos. No entanto, uma boa dose de bom senso (e bastante experiencia acumulada) é necessária para temperar as decisões. Se se seguissem à risca os critérios formais, grande parte da produção seria rejeitada, sobrecarregando as operadoras (que deveriam refazera reinspeção a 100\%), atrasando a produção em outros setores e elevando os estoques intermediários. Em verdade, os criterios de decisão efetivamente utilizados pelas controladoras de qualidade (a seu custo e risco) são muito mais variados $e$, sobretudo, mais eficazes. Elas levam em conta, antes de rejeitar um lote, a história do defeito (o tipo, o momento em que ele aparece, sua frequência e distribuição), a experiência e as particularidades da operadora que o inspecionou, a máquina de onde veio a peça, a gravidade do defeito, etc. Tudo isto faz cont que elas nuancem suas decisões, contrariando as regras existentes, recusando ora todo um horário de produção, ora apenas a parte do lote do que passou por uma dasoperadoras, ora uma parte das bandejas, ora apenas a bandeja em que foi encontrado o produlo defeituoso. Suas decisões, verdadeiramente racionais, são fundadas num profundo conhecimento do funcionamento real do processo e das pessoas com quem ela trabalha, saber que dificilmente pode ser colocado sob a forma de procedimentos técnicos precisos e univocos?

\section{Conclusão: Pela}

\section{Livre Organizacão dos Produtores Associados}

É impossivel não reconhecer, hoje, a importância da "iniciativa" e "colaboração" dos trabalhadores para fazer funcionar com eficiência a produção. Até mesmo Taylor, à sua maneira, como vimos, reconhecia e valorizava a "iniciativa" dos de baixo e colocava em termos de "cooperação" a relação entre gerentes e operários, uma vez que as responsabilidades pelo desenvolvimento e organização da produção e do trabalho deviam ser "eqüitativamente" (leia-se hierarquicamente) divididas. Assim, desde que os trabalhadores dessem prova de inteligência suficiente, eles poderiam colaborar e dar sugestões para o desenvolvimento da ciência do trabalho. A questão, portanto, não é simplesmente a "participação", mas a forma como ela se dá. Assim, sob o discurso pretensamente humanista inspirado em Maslow, é o velho taylorismo de outrora que reaparece sob os traços orientali-

\footnotetext{
7- A in'acionalidade da padronização aparece conn nais evidência na forma de organização prescrita pela gerência. Coerentemente con a crença de que as decisões devam ser impessoais, objetivas e não subjetivas, propugnava-se o rodizio entre as controladoras de qualidade, para que não se criassem laços de annzade com as operadoras, o que poderia perturbar as decisões. Somente depois de muito custo, e quando se veirficou a dificuldade en adquirir a experiência necessária, é que se tixaran as contrcladoras deste setor.
} 
zados da GQT. É preciso, no entanto, mais que simples boa-vontade para resolver as contradições e conflitos do mundo do trabalho ${ }^{8}$.

No caso da padronização dita "participativa" e apoiada no consenso, a situação não é diferente. É significativo, por exemplo, que a "delegação" somente se dê com base (e nos limites) na padronização. A participação em nada altera a essência burocratizante da padronização, a não ser na eventual (e terrivel) possibilidade de que os próprios trabalhadores criem seus grilhões. $O$ objetivo taylorista de extrair e controlar o saber-fazer dos operários é agora obtido com a participação, sendo que tudo o mais permanece; o retorno do controle da gerência verificando a execução do trabalho, segundo o the one best way. Nestas condições, o que de fato acontece é que o padrão adquire o caráter de uma sociabilidade externalizada que, mesmo sendo estabelecida com a colaboração dos executantes, se volta contra eles, dominando-os e obrigando-os a seguirem procedimentos que rigidificam o trabalho realmente criativo e eficiente. $A$ "padronização participação" se transforma assim na "participação padronizada", pré-figurando a anti-utopia de uma desventurosa sociedade de autômatos, onde os próprios agentes criariam os mecanismos de controle. O padrão, além de ser profundamente patológico e burro, nada mais é que o mínimo necessário, e não o que permite desenvolver a produção; não se resolve problemas dentro dos padrões, mas fora deles, pois problemas reais não ocorrem segundo os padrões préestabelecidos.

A adoção dessas técnicas e princípios tayloristas representa um triste anacronismo, sobretudo quando se verifica a ineficiência do assim chamado "modelo taylorista-fordista" para organizar a produção de sistemas complexos, onde a flexibilidade, interligação sistêmica e variabilidade (em suma, a complexidade) tendem a se impor sobre a repetibilidade. (que, já vimos, nunca realmente existiu, a não ser na cabeça de alguns organizadores e engenheiros... que insistem em repetir Taylor). O controle desses sistemas complexos exigem novas competências e formas de ação pouco apropriadas para serem padronizadas e enquadradas em comportamentos rígidos $\mathrm{e}$ burocratizados. É interessante observar que sistemas de produção minimamente mecanizados já não comportam procedimentos operacionais detalhados, porque a variabilidade do sistema e a atividade dos operadores são demasiadamente complexas para serem formalizadas. Os padrões se resumem, nesses casos, a regras gerais de bem pouca serventia para o controle efetivo do processo?. Mas contrariamente a toda marifestação de racionalidade e de bom senso, a GQT pretende ser possivel identificar processos repetitivos (onde seria pertinente a instituição de padrões) em

\footnotetext{
8- A indigência teórica dos prosélitos da QT è particulannente acentuada no que se refere à fonnação en teoria organizacional e ciências humnanas em geral. Trata-se, como dissemos, de engenheiros e técnicos que, imbuidos de sincera boa-vontade, querem transfonnar o mundo da produção anuados con singelos principios e conceitos abstratos, incapazes, portanto de entender e apreender as contradições da realidade que pretendem mudar. A inefetividade desses votos piedosos aparece tão logo se procure observar com mais cuidado os resultados reais dos progranas de QT e a forna como eles foram implementados. Também aqui, a GQT em nada fica devendo à Taylor Tanto Ium como noutro caso, as efetivações dos principios só foran possiveis após uma severa seleção, explicita ou inplicita, não só procurando escolher o "homen certo para o lugar certo" mas sobrendo eliminar aqueles mais teimosos, ou seja, os que se recusavan a colabotar. A adesão só é conseguida sob coerção, processo que no Japão tomou a forna mais sutil da cooptação através de contrapartidas salariais e de (relativa) estabilidade no emprego, mas tambèn através da substituição de sindicatos livres pelos sindicatos por empresas. Tudo isso criou condiçốes para que ai ocorresse o que Coriat(1991) denominou de "implicação incitada". A "seleção cientifica" é, na prática, seleção de conpos e mentes dóceis. Para obtê-los, é necessáno, antes, individualizar a relação entre a gerểncia e os trabalhadores, excluiudo qualquer fomna de organização ou representação de classe (sempre taclıadas de corporativas), pernitindo desınainchar as diversas fonnas de resistência coletiva, fomais e informais. Evidência suficiente de que a objetividade dos conflitos sociais transcende os falsos cliscursos e hamonias pré-estabelecidas.
} 
todas as atividades humanas, até mesmo naquelas mais criativas (como o trabalho de projetistas) ou intrinsecamente variadas, como o ensino (COELHO \& XAVIER, 1993). Ora, é precisamente num momento onde a produção de bens e serviços passa por profundas transformações, uma das caracteristicas sendo o aumento proporcional das atividades terciárias, que se procura um modelo ultrapassado e inspirado na produção do tipo manufatureira. Sem compartilharmos as análises e conclusões de Offe (1989) sobre o fim da "sociedade do trabalho", concordanos com a afirmação de que o trabalho em serviços possui "uma racionalidade própria", bastante imprópria à padronização ${ }^{10}$.

Para sugerir a alternativa possível, é interessante retomar um dos exemplos que servem para sustentar as vantagens e a inevitabilidade da padronização: a linguagem. Dizer que a padronização é a base do controle e do desenvolvimento da produção, seria equiva- lente a afirmar que a gramática seria responsável pela produtividade da linguagem ou assimilar o pensamento aos seus aspectos expressivos formais. No entanto, é pouco provável que consigamos explicar a produtividade da linguagem e do pensamento, simplesmente pela sintaxe, ou através das significações das palavras, tal como expostas nos dicionários ${ }^{11}$. Da mesma forma, o aspecto verdadeiramente rico e criativo do trabalho não se encontra nos procedimentos formalizados e unificados dos padrões, mas na versatilidade e relativa indeterminação do trabalho vivo, sempre capaz de perceber as múltiplas possibilidades de uma situação, e escolher dentre elas. Esta é, aliás, a razão última do trabalho ser indispensável na condução do processo de produção, o que faz da fábrica sem trabalhadores apenas um mito. Para responder adequadamente à inevitável variabilidade e imprevisibilidade dos processos produtivos, são necessárias ações corretivas, de antecipação e de resolução de problemas cuja

\footnotetext{
9- Pesquisas em andanesto en várias empresas certificadas pela ISO 9000, tem revelado alguıs dados curiosos: a imiação do pessoal de produção conn as minúcias inuteis de procedimentos que thes são impingidos pelo pessoal de qualidade; a confecção de manuais que quase sempre fican engavetados, sendo retirados somente nos momentos das anditorias; a recitaçäo dos proceditnentos, somente para agradar aos auditores (e para receber os prênuos oferecidos a quem não "enrar" as respostas). Descobriu-se que a obtenção do certificado está vincul ada a una larga experiência anterior, founal ou infornal, e a uma lustória sempre voltada à produção con qualidade. Dizia-se que "a ISO 9000 nada mais é que formalizar o que sempre fizemos". A conclusão necessána é que a ISO 9000 tên servido sobretudo como apelo de marketing e como importante vantagem competitiva, mas con poucos efeitos diretos ua produção. Hoje, a posse de unn certificado ISO 9000 passa a ser un pré-requisito para competir em mercados nacionais e intemacionais, e pode ser a garantia de manutenção da posição de una empresa, sobretudo quando, à febre da qualidade, se junta a estratégia de flexibilização dos fonecedores eII escala mundial. O risco é acreditar que se pode colocar sob a fonna de regras aquilo que "sempre fizenos", ainda pior quando algumas mentalidades especialmente burocráticas (via de regra, gerentes de qualidade) querem que a produção siga à risca tudo o que se colocon no papel.
}

\footnotetext{
to. Offe(1989:23) explica que "por causa da falta de homogeneidade, da descontiutudade e da incerteza ternporal, social e material dos "casos" tratados pelo trabalho em serviços, frequientemente não é possivel (a não ser com consequências contraproducentes) nornnatizar uma função técnica de produção para o traballı, a ser adotada como criténio de controle de execução do trabalho." Por conseguinte, "no que se refere à racionalidade técruca do trabalho en serviços, a crescente incapacidade de sıa nonnatização tem que ser compensada por virtudes como a capacidade de interação, o senso de responsabilidade, a empatia e a experiência adquirida casuisticamente". Como vinnos, antes de serem caracteristicas exclısivas do traballı etm serviços (são apenas mais evidentes), a variabilidade e a incerteza são traços ontológicos de qualquer atividade humana, persistentes até mesmo nos trabalhos inais rotineiros, realidade que é sonnente encoberta pela ilusão mecanucisla dos engentheiros, criada pela necessidade de se adequar o processo de traballıo às formas abstratas do valor de troca e do processo de valorização

"- Para entender as limitações do fornalismo, è preciso distinguir entre "sentido" e "siguifícação" de uma palavra. "Como se sabe, a palavra inuda facilmente de sentido, segundo o contexto. A siguificação, ao contránio, é un ponto inóvel e imutável, que fica estável a despeito de todas as modificações que afetan, segundo o contexto, o sentido da palavra." A maior riqueza do sentido emn relação à significação de una palavra fica evidente: "a palavra tomada isoladamente e dentro do dicionário possui unna só siguificaçăo. Mas essa signiticação nada thais é que uma potencialidade que se realiza na linguagen viva, onde ela é apenas una pedra no edificio do sestido."(VYGOTSKY, 1985:370)
} 
natureza heurística (não meramente procedural) ainda continua sendo exclusividade do homem (apesar dos avanços significativos em inteligência artificial).

Ao contrário do que possa parecer aos leitores mais afoitos ou àqueles mais afeitos à tradição, nossa posição nada tem a ver com um anarquismo radical, que negaria qualquer forma de autoridade ou regulação coletiva, mas procura simplesmente apontar os limites e a ineficácia dos controles externos sobre a atividade de trabalho (e humana em geral) no interior da complexidade concreta das relações sociais e da produção material. Também o direito oferece um paralelo esclarecedor. $\mathrm{O}$ princípio formal de justiça, segundo o qual "todos são iguais perante a lei", é, em verdade, injusto e desumano, pois trata desiguais como se fossem iguais. Neste sentido, nada mais faz que refletir a lógica da troca de mercadorias, urdidura da forma de socialidade capitalista, somente possivel pela identidade dos valores de troca. Diferentemente, Marx postula um princípio para além da justiça (HELLER, 1990), expresso no lema "de cada um segundo suas possibilidades, a cada um segundo suas necessidades". Este princípio pressupõe que cada indivíduo se transforme em seu próprio juiz, inclusive para definir a sua "jornada normal de trabalho", ou asua "melhor maneira de trabalhar". Não se trata aqui de nenhuma utopia, mas de reconhecer necessidades que já são satisfeitas quase sempre de forma implicita, generalizada na seguinte fala de um trabalhador: "Jamais um operário fica diante de sua máquina pensando: só faço o que me dizem" (SCHWARTZ, 1988). A realidade do comportamento no trabalho mostra que a regra não é o cumprimento estrito de regras, mas recriação permanente, quase sempre de forma clandestina. Trata-se, portanto, de reconhecer essa realidade e criar novas relações sociais para que esta realidade em germe possa se desenvolver plenamente e à luz do dia. Contudo, uma outra concepção de organização da produção e do trabalho, que se fundamente não no trabalho morto, no já existente, mas na potencialidade do trabalho vivo, só pode se desenvolver e se expressar através da livre organização dos produtores associados e não na sociedade hierarquizada que preserva poderes e desigualdades materiais sob a aparente igualdade de direitos e de procedimentos da democracia formal. $O$ trabalho vivo (e livre) é tão antipadrão quanto anti-patrão: somente a livre organização dos produtores pode propiciar condições para que as regras criadas sirvam como suporte para a atividade criativa e não como restrição absurda ${ }^{12}$.

\section{Referências Bibliográficas}
CAMPOS, V.F.Padronização de empresas. Belo Horizonte, Fundação Christiano Ottoni, 1992a

CAMPOS, V.F.TQC: controle da qualidade total. Belo Horizonte, Fundação Christiano Ottoni, 1992b

\footnotetext{
12 - Apesar da visão piagetiana da cooperação conno "mélodo", o que implica valorizar os procedinentos fonnais da deınocracia burguesa, en detrimento de uma concepcão substantiva, concordamos que "o sisteına democrático pede a cooperação. Basta verificar quais são suas exigências, levar en conta o ponto de vista allıeio, respeita-lo, fazer acordos, negociações, contratos com o outro, adınitir e respeitar as diferenças individuais, conviver com a pluralidade de opiniões, de crenças, de credos, etc. Aléın do mais, pelas características do mundo modenio, somos cada vez mais levados a ter de encontrar e nos relacionar com pessoas de culturas diversas, de formação diversa, de religiões diversas. Ven dai que o ideal da "padronizaçäo" dos comportannentos tonıa-se totalinente impossivel de ser realizado. Como diz Piaget, a nova exigência é de coordenar os diversos pontos de vista e diferenças, e não mais de reduzi-los através de mođelos a serein itnitados por todos." ( La TAILLE, 1992:69) Evidenteınente que a questäo não fica ainda resolvida, pois é preciso mostrar como evitar o relativismo que sempre espreita o respeito indiferenciado da diferença, e como criar una base comum de ação suficientemente flexivel para não eliminar, na prática, as diferenças recondecidas como legitimas. Mas isto é uma outra conversa.
} 
COELHO, M.I. de M. \& XAVIER, G. G. "Padronização como elaboração participativa e critica dos profissionais". In: BARBOSA et al.Gerência da qualidade total na educação. Belo Horizonte, Fundação Christiano Ottoni, 1993.

CORIAT, B. Penser à l'envers. Paris, Christian Bourgeois, 1991.

DORAY, B. Le taylorisme, une folie rationnelle? Paris, Dunod, 1981.

HELLER, A. Mas allá de la justicia. Barcelona, Editorial Critica, 1990.

La TAILLE, Y. et al.. Piaget, Wygotsky, Wallon. São Paulo, Summus, 1992(3a ed.).

LIMA, F.P.A."Qualidade Total e reorganização produtiva". Anais do XIII ENEGEP. Florianópolis, 1993.

LUKÁCS, G. Socialisme et démocratisation. Paris, Editions Sociales, 1989.

MANDEL, E. Socialismo $x$ mercado. São Paulo, Ensaio, 1991
MONTMOLLIN, M de.Le toylorisme à visage humain. Paris, PUF, 1981.

MORAES NETO, B.Marx, Taylor e Ford. São Paulo, Brasiliense, 1989.

OFFE, C.Trabalho e sociedade. Rio de Janeiro, Tempo Brasileiro, 1989.

SCHWARTZ, Y.Expérience et connaissance du travail. Paris, Editions Sociales, 1988

TAYLOR, F.W.Princípios de administração cientifica. São Paulo, Atlas, 1970.

TERSSAC, G. de \& DUBOIS, P. (org) Introduction à Les nouvelles rationalisations de la production. Toulouse, Cépaduès Editions, 1992.

THOMPSON, J.B. \& HELD, D.Habermas, critical debates. London, MacMillan Press, 1982.

WYGOTSKY, L.S.Pensée et langage. Paris, Editions Sociales, 1985. 